\title{
AC 2010-414: PROFESSIONAL PRACTICE SIMULATION FOR UNDERGRADUATE ENGINEERS: A TOOL FOR ENGAGING, EDUCATING AND ASSESSING
}

Naomi Chesler, University of Wisconsin, Madison

Elizabeth Bagley, University of Wisconsin, Madison

Eric Breckenfeld, University of Wisconsin, Madison

Devin West, University of Wisconsin, Madison

Alison Stace-Naughton, Dartmouth College

David Shaffer, University of Wisconsin, Madison 


\title{
Professional Practice Simulation for Undergraduate Engineers: A Tool for Engaging, Educating and Assessing
}

\begin{abstract}
We are developing a novel computer simulation game based on authentic engineering practices to give first-year engineering undergraduates a more complete and accurate understanding of the engineering profession. The game is student-focused in that it is tailored to the newest generation of engineering students who are more computer literate, electronically connected, and simulation game-oriented than any prior generation. The game also is epistemic frame-based in that it seeks to teach and assess the degree to which students acquire the skills, knowledge, values, identity, and epistemology (i.e., the epistemic frame) of the engineering profession. We anticipate that this approach will be highly engaging to first-year undergraduate engineering students and help promote the development of their engineering epistemic frame.
\end{abstract}

\section{Introduction}

The idea that members of a profession have a common "way of viewing the world" or particular "habits of mind" is well accepted. However, studying the development of a professional way of viewing the world in students of that profession requires discrete, quantifiable aspects. The epistemic frame hypothesis posits that the skills (the things that professionals do); knowledge (the understandings that professionals share); values (the beliefs that professionals hold); identity (the way that professionals see themselves); and epistemology (the ways of knowing shared by professionals) are critical factors in the development of a professional way of viewing the world. These five attributes - skills, knowledge, values, identity and epistemology - make up the epistemic frame.

Prior work has shown that a key step in developing the epistemic frame of many professions, especially those that require innovation, is some form of professional practicum ${ }^{1,2}$, which is an environment in which a learner takes professional action in a supervised setting and then reflects on the results with peers and mentors. Skills and knowledge become more and more closely tied as the student learns to see the world using the epistemic frame of the profession. Examples of professional practica include capstone design courses in undergraduate engineering programs, medical internships and residencies, or almost any graduate program in STEM disciplines. Prior work has also shown that epistemic games-learning environments where students game-play to develop the epistemic frame of a profession-increase students' understanding of and interest in the profession ${ }^{3-5}$.

In this paper, we present the development of Nephrotex, a novel epistemic game in which undergraduate engineering students role-play as professional engineers-in-training in order to develop the skills, knowledge, values, identity, and epistemology of engineers. Our approach is novel in several ways. First, our game, which has aspects in common with first year design courses $^{6,7}$, is offered not in isolation but as part of a simulated workplace environment for established professionals in practice. Thus, the learning develops in context ${ }^{7}$ and the experience has the potential to more realistically mimic the engineering experience. Second, we enable all activities to be done in a simulated environment with some automation to interactions, which 
reduces instructor and client time demands and enhances the potential for scale-up to more and larger institutions. Third, we incorporate a data collection platform that has the potential to dramatically improve assessment of learning outcomes through qualitative and quantitative formative and summative evaluation.

\section{Methods}

In Nephrotex, students are welcomed as early career hires into the fictitious company Nephrotex, whose core technology is the ultrafiltration unit, or dialyzer, of a hemodialysis machine. Two commercially available dialyzers are shown in Figure 1. The students' assigned task is to design a next-generation dialyzer that incorporates carbon nanotubes into the hollow fibers that filter toxins out of the patient's blood. This task is assigned to them by the head of research and development, a nonplayer character, and explained to them in depth by their engineering manager, a live mentor, who also supplies some introductory background material.

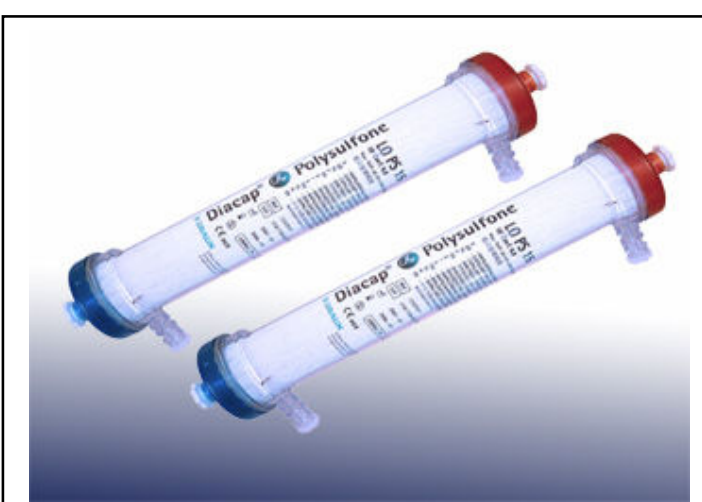

Figure 1. Commercially available dialyzers from CVP Medical Technology ${ }^{8}$. Because the virtual environment is constrained, students will be able to vary only four elements of the dialyzer: hollow fiber material, percent carbon nanotubes, material processing method and surfactant. Their design choices will be evaluated on the basis of cost, biocompatibility, marketability, reliability and ultrafiltration coefficient. One key element to developing the engineering epistemic frame is that there is no optimal solution to the problem. That is, there is no solution for which cost is minimized and the other performance criteria are maximized. Students will have to find the solution(s) that best meet criteria of a diverse set of stakeholders, which is an important part of the engineering professional practice. In Nephrotex, the stakeholders are a clinical engineer, a manufacturing engineer and representatives from marketing and product support, all of whom are non-player characters like the head of research and development. Each stakeholder is only concerned with a subset of the performance criteria, and the priorities of the stakeholders can be in conflict. For example, the representative from marketing is very concerned with marketability and cost whereas the clinical engineering cares more about biocompatibility and the ultrafiltration coefficient. If increasing the ultrafiltration coefficient necessarily increases cost, these two stakeholders will rarely agree on an optimal device design. The students, then, must find a device design that is acceptable to all stakeholders, even if it is not optimal according to all stakeholders. This "satisficing strategy" is an important element of the engineering professional practice.

To meet the ultimate objective, students will be guided through a series of activities, including several design-build-test (DBT) cycles (Figure 2). These increasingly complex research and design tasks will be conducted individually and in small groups. All activities will take place within the context of an existing first-year engineering design course as a module of 12 50minute classes. The activities will focus on engineering skills (e.g., graphical and written communication, literature research and interpretation, working within teams) and knowledge (e.g., basic transport phenomena, manufacturing, nanotechnology, tradeoffs in design) as well as identity (often promoted through interaction with clients ${ }^{9}$ ), values (potentially by attempting to meet the conflicting demands of various stakeholders) and epistemology (by all of the above). 
Student work output will be analyzed for evidence of development of epistemic frame elements at several time points throughout the module. We anticipate piloting the game in Fall 2010 and using the data collected to refine the game for broader distribution.

\section{Conclusions}

We predict that this approach will be highly engaging to first-year undergraduate engineering students, successfully develop their engineering epistemic frame, and also provide a wealth of data for assessment of learning and professional development that can inform the design of future course, curriculum and learning innovations in engineering disciplines.

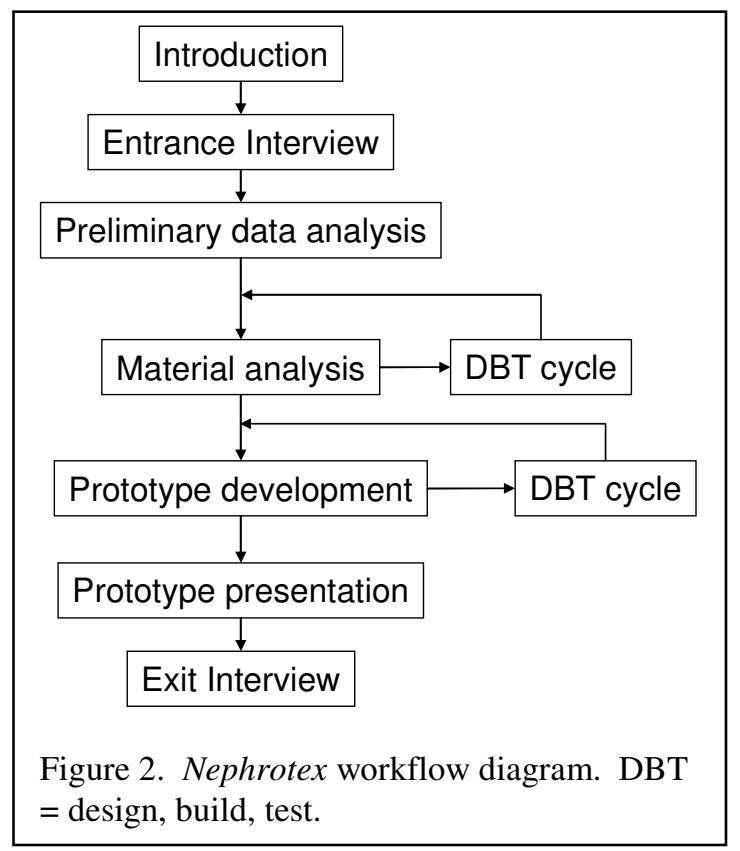

\section{Acknowledgements}

This material is based on work supported by the National Science Foundation under grants DUE0919347 and EEC-0938517.

\section{Bibliography}

1. Schon, D.A., The reflective practitioner: How professionals think in action. 1983, New York: Basic Books. $\mathrm{x}$, 374.

2. Schon, D.A., Educating the reflective practitioner: Toward a new design for teaching and learning in the professions. 1987, San Francisco: Jossey-Bass.

3. Shaffer, D.W., How Computer Games Help Children Learn. 2007, New York: Palgrave.

4. Svarovsky, G. and D.W. Shaffer, SodaConstructing knowledge through exploratoids. Journal of Research in Science Teaching, 2007. 44(1): p. 133-153.

5. Bagley, E.A.S. and D.W. Shaffer, When people get in the way: Promoting civic thinking through epistemic gameplay. International Journal of Gaming and Computer-Mediated Simulations, 2009. 1(1): p. 36-52.

6. Dym, C., et al., Engineering Design Thinking, Teaching and Learning. Journal of Engineering Education, 2005. 94(1): p. 103-120.

7. Paretti, M.C., Teaching Communication in Capstone Design: The role of the instructor in situated learning. Journal of Engineering Education, 2008. 97(4): p. 491-503.

8. http://www.cvpmed.com/photo/dialyzer1.jpg

9. Svarovsky, G, Unpacking the Digital Zoo: An analysis of the learning process within an engineering epistemic frame. Doctoral Dissertation, University of Wisconsin-Madison Department of Educational Psychology, 2009. 